\title{
Overwork and Adverse Effects on Health
}

\section{Tetsuji Yamada ${ }^{1 *}$, Tadashi Yamada ${ }^{2}$, Chia-Ching Chen $^{3}$ and Weihong Zeng ${ }^{4}$}

${ }^{1}$ Department of Economics and Center for Children and Childhood Studies Rutgers University, the State University of New Jersey, USA ${ }^{2}$ Graduate School of Humanities and Social Sciences, Institute of Policy and Planning Sciences, University of Tsukuba, Tsukuba, Japan ${ }^{3}$ Department of Epidemiology and Community Health, School of Health Sciences \& Practice, New York Medical College, New York, USA ${ }^{4}$ School of Public Policy and Administration, Xi'an Jiaotong University, China

\begin{abstract}
The Japanese Government reports that the health of Japanese employees deteriorated in the 1990s - 2000s during the Japanese recession. This paper examines the relationship between overtime work and health of employees. We present a theoretical model showing that overtime work causes an individual's health to deteriorate. This is based on the hypothesis that overtime work is implicitly built into a firm's promotion system. Using the data of 6,985 individuals from the first National Family Research in 1998 (NFR98) provided by the Social Science Japan Data Archive, Institute of Social Science, University of Tokyo, our empirical results support our hypothesis and show strong associations among overtime work, health and socio-economic characteristics of individuals, as well as labor market conditions.
\end{abstract}

Keywords: Overtime work; Health; Promotion

\section{Introduction}

Overtime work is prevalent in the Japanese labor market $[1,2]^{1}$. A survey made by the Japanese Trade Union Confederation (RENGO, in Japanese) in 2002 shows that the average of paid overtime work hours in the month in June 2002 was 21 hours per union member ${ }^{2}$. Furthermore, the average unpaid overtime work hours were 8.7 hours $^{3}$. On the other hand, Japanese government statistics report rather low overtime work hours; the highest monthly-average paid overtime work hours per person in 2002 are 14.3 hours in firms with over 500 regular employees; the lowest are 7.0 hours in firms with 5-29 regular employees ${ }^{4}$. Regardless of low or high reported statistics of overtime work hours, the distribution of overtime work among employees is not uniform in the Japanese labor market.

Concerning the health of Japanese employees, total mental illness applications rose abruptly from 1998 to 2001. There was also a dramatic increase in the number of suicides in the late 1990s. The

${ }^{1}$ Overwork is not a peculiar aspect only in Japan, but also in the US and European countries (Bejean, Sultan-Taïeb and Wolff 2003; Brett and Stroh 2003).

2 The Japanese Trade Union Confederation (RENGO), the Current Situation of Increasing Job Burdens and Unpaid Overwork under Employment Restructure the Survey Results (Temporary Report) from the 2002 RENGO Life Questionnaire -, Table 1. In Japanese, "Koyou Risutra no Naka-de Taka-maru Sigoto no Fuka to Fuba-rai Zangyo no Zittai - 2002 Rengo Seikatsu Ankeito Chosa kekka (Soku-ho) Zittai."

http://www.jtuc-rengo.or.jp/new/download/chousa/2002_seikatu_enq/2002life enq_sok.pdf.

${ }^{3}$ According to the survey, the average unpaid overtime work hours are 29.6 hours among union workers who worked unpaid.

${ }^{4}$ Paid overwork hours beyond contractual work hours are called "Shotei gai Rodo Zikan" in Japanese. Source: Ministry of Health, Labor and Welfare, database system, statistical table, Table 1 Average monthly actual work hours per person by regular employee divided by scale of sector. http://wwwdbtkmhlw.go.jp/toukei/ touhyo/indexkr $14 . \mathrm{html}$

${ }^{5}$ From the original data of Equation 1, we recognize the numbers of recognition of these two types of illness are very low relative to the total applications; the applications of brain blood vessel disease and ischemic heart disease are 509 and 241 in 2001, respectively, while their respective recognitions are 150 and 49.

${ }^{6}$ Gerdtham and Ruhm (2002), Ruhm (2003) , and Grossman (2004) support the idea that health improves in a recession.

${ }^{7}$ Grossman (1972) shows good or better health results in more days available for work of an individual. number of recognition of total physical illness, including brain blood vessel disease and ischemic heart disease, etc, showed increasing trends in the 1990s, when Japan experienced severe economic recession ${ }^{5}$.

The Adverse effects of overwork on an employee's health, especially sudden death from overwork [3], have become a hotly debated social issue. Sudden death due to cardiovascular and cerebro vascular disease seems to be caused by high job strain [3]. The aforementioned RENGO survey indicates union workers become more anxious about their health as they work more hours beyond contractual hours [5-7] $]^{6}$. In addition, according to the First National Family Research in 1998 (NFR98: the sample size $\mathrm{N}=6,985$ ) made by the Japan Society of Family Sociology, less healthy people work fewer hours than those in better health see Tables 1 and $2[4]^{7}$.

Why do employees accept overwork in their workplace, while the epidemiological relationship between overwork and its adverse effects on health cannot be ignored? [1,2] Provide one answer for the behavior of longer work hours by US male and female managers: people in a higher job status with more responsibility seek the higher monetary rewards from long hours as well as experiencing peer pressure and seeking an emotional respite from home. In fact, their US study reports work stress is associated with longer work hours among male managers, as the above RENGO survey shows with Japanese union workers.

The purpose of this study is twofold: first, we provide a theoretical model to explain why Japanese employees choose excessive paidand unpaid-overtime work despite its adverse effects on their health. Second, we empirically test if an individual's health improves during a recession with Japanese data, as with US data by $[5,6]$, since an abrupt increase in the number of health problems with Japanese employees

*Corresponding author: Tetsuji Yamada, Department of Economics and Center for Children and Childhood Studies Rutgers University, the State University of New Jersey, USA; Tel: 1-856-225-6025; E-mail: tyamada@crab.rutgers.edu

Received December 12, 2013; Accepted December 27, 2013; Published Janaury 05, 2014

Citation: Yamada T, Yamada T, Chen CC, Zeng W (2014) Overwork and Adverse Effects on Health. J Glob Econ 2: 106. doi:10.4172/2375-4389.1000106

Copyright: @ 2014 Yamada T, et al. This is an open-access article distributed unde the terms of the Creative Commons Attribution License, which permits unrestricted use, distribution, and reproduction in any medium, provided the original author and source are credited. 
Citation: Yamada T, Yamada T, Chen CC, Zeng W (2014) Overwork and Adverse Effects on Health. J Glob Econ 2: 106. doi:10.4172/23754389.1000106

Page 2 of 8

\begin{tabular}{|c|c|c|c|c|c|c|c|c|}
\hline \multirow[b]{2}{*}{ Age } & & \multicolumn{7}{|c|}{ Work Hours per Month } \\
\hline & & 0 hour & $1 \sim 80$ hours & $81 \sim 160$ hours & $161 \sim 240$ hours & $241 \sim 320$ hours & $321 \sim 400$ hours & Total \\
\hline \multirow{2}{*}{$\begin{array}{l}\text { Less than } \\
40 \text { years old }\end{array}$} & Number of People & 34 & 2 & 140 & 487 & 107 & 20 & 790 \\
\hline & Ratio of those people in poor health & 0.236 & 0.000 & 0.093 & 0.109 & 0.131 & 0.100 & 0.114 \\
\hline \multirow{2}{*}{$40 \sim 49$ years old } & Number of People & 35 & 6 & 146 & 411 & 110 & 22 & 730 \\
\hline & Ratio of those people in poor health & 0.343 & 0.334 & 0.090 & 0.098 & 0.155 & 0.182 & 0.121 \\
\hline \multirow{2}{*}{$50 \sim 64$ years old } & Number of People & 163 & 17 & 250 & 529 & 98 & 24 & 1081 \\
\hline & Ratio of those people in poor health & 0.344 & 0.412 & 0.184 & 0.137 & 0.154 & 0.167 & 0.185 \\
\hline \multirow{2}{*}{$\begin{array}{l}\text { Total (Less than } 65 \text { years } \\
\text { old) }\end{array}$} & Number of People & 232 & 25 & 536 & 1427 & 315 & 66 & 2601 \\
\hline & Ratio of those people in poor health & 0.328 & 0.360 & 0.135 & 0.116 & 0.147 & 0.152 & 0.145 \\
\hline
\end{tabular}

Note:

a) person in poor health refers to a person who reported that 「health condition is worse $\rfloor$ or $\lceil$ health condition is the worst $\rfloor$

b) the number of persons under 39 years old and working for 0 days monthly is 32 , and $25 \%$ of them are reported to be in poor health

Source: The First National Family Research in 1998 (NFR98), The Social Science Japan Data Archive, Institute of Social Science, University of Tokyo.

Table 1: The relationship between health condition and wok hours (Male).

\begin{tabular}{|c|c|c|c|c|c|c|c|c|}
\hline \multirow[b]{2}{*}{ Age } & & \multicolumn{7}{|c|}{ Work Hours per Month } \\
\hline & & 0 hour & $1 \sim 80$ hours & $81 \sim 160$ hours & $161 \sim 240$ hours & $241 \sim 320$ hours & $321 \sim 400$ hours & Total \\
\hline \multirow{2}{*}{$\begin{array}{l}\text { Less than } \\
40 \text { years old }\end{array}$} & Number of People & 346 & 95 & 250 & 174 & 9 & 0 & 874 \\
\hline & Ratio of those people in poor health & 0.116 & 0.148 & 0.112 & 0.098 & 0.111 & 0.000 & 0.114 \\
\hline \multirow{2}{*}{$40 \sim 49$ years old } & Number of People & 209 & 103 & 276 & 182 & 14 & 0 & 784 \\
\hline & Ratio of those people in poor health & 0.177 & 0.136 & 0.138 & 0.143 & 0.072 & 0.000 & 0.148 \\
\hline \multirow{2}{*}{$50 \sim 64$ years old } & Number of People & 519 & 124 & 279 & 245 & 44 & 9 & 1220 \\
\hline & Ratio of those people in poor health & 0.237 & 0.153 & 0.176 & 0.143 & 0.205 & 0.222 & 0.194 \\
\hline \multirow{2}{*}{$\begin{array}{l}\text { Total (Less than } 65 \\
\text { years old) }\end{array}$} & Number of People & 1074 & 322 & 805 & 601 & 67 & 9 & 2878 \\
\hline & Ratio of those people in poor health & 0.186 & 0.146 & 0.143 & 0.130 & 0.164 & 0.222 & 0.157 \\
\hline
\end{tabular}

Note: See note of table 1

Table 2: The relationship between health condition and wok hours (Female).

occurred during recessions after the burst of the bubble economy in 1990. Therefore, unlike the U.S. case, the health of Japanese employees seems to deteriorate during a recession. To empirically test our hypotheses on the relationship between overtime work and the health of employees, we use micro data of 6,985 Japanese individuals from the first National Family Research in 1998 (NFR98) made by the National Family Research of Japan (NFRJ) of the Japan Society of Family Sociology (JSFS: Nihon Kazoku Shakai Gakkai, in Japanese).

Our empirical findings support the hypothesis that overtime work is systematically built into the promotion structure in Japanese firms and, hence, employees tend to choose overtime work despite the adverse effects on health. Of the relationship between overtime work and health, we find employees with good health tend to work overtime, but excessive overtime work eventually causes their health to deteriorate. Ultimately, employees with health problems reduce their labor supply in the market. We consequently propose a review of worker-employer implicit relationships to establish an explicit and objective evaluation system for job promotion.

Section II presents our theoretical model of the behavior of overtime work of the employees in a context of the theory of expected utility of income. Our empirical results are reported in Section 5 and the summary and conclusion are in Section 6.

8 "Regular" employees imply the workers who are hired on an implicitly permanent basis by their contracts with firms. They are generally entitled to various kinds of fringe benefits and are in line for job promotion in the firm, unlike temporary or parttime workers. Hereafter, we use employees synonymous with regular employees.

${ }^{9}$ A typical employee is either female or male in our text. Since overtime work is a typical phenomenon and more prevalent among male regular employees than female employees in Japan, we treat a typical employee as male to avoid a clumsiness of saying "his or her" every time.

\section{A Theoretical Model of Overtime Work and Health of Employee}

The purpose of this section is to provide a theoretical model to explain why overtime work is prevalent among regular employees in $\mathrm{Japan}^{8}$. There are at least three reasons why employees are willing to work overtime.

First, we consider the employee's incentive to work overtime as a signal of the individual's commitment to the firm where they work. Employees know their paid- and unpaid-overtime work incentives are intrinsically built into a job promotion system in the firm. Therefore, overtime work is a tactic for a typical employee to maximize their individual labor earning through job promotion. Second, overtime work has another aspect reflecting the employee's lack of competency in their job. That is, a typical employee can mask his or her lack of competency to some degree by showing their commitment to the firm through overtime work. Third, since the parameter reflecting the firm's evaluation on employee's incentive for overtime work is not clearly specified in the labor contract between the firm and the employees, a risk adverse attitude leads a typical employee to work overtime. In a typical case, by misinterpreting the parameter the employee commits excessive overtime work, which eventually causes deterioration in health.

In our theoretical model, we assume a typical employee maximizes his or her discounted expected utility of income in two periods $t=0$ and $t=1$, as follows 9 .

$$
E[U(Y)]=P\left(H_{0}\right) U\left(Y_{0}\right)+P\left(H_{1}\right) \rho U\left(Y_{1}\right),
$$

Where $H_{t}$ is the health stock of a typical employee at time $t$ : 
a larger value of $H$ implies better health of the individual; $P\left(H_{t}\right)$ is the probability reflecting the individual's health condition,

$$
\frac{\partial P\left(H_{t}\right)}{\partial H_{t}} \equiv P_{H_{1}}>0 ; Y_{t} \text { is his income from labor; and }
$$

$0<\rho<1$ is a discount factor. Of equation (1), we assume $U\left(Y_{t}\right)$ takes a form of $\ln Y_{t}$ for our operational purpose.

The employee chooses optimal hours of overtime work per period to maximize his discounted expected utility of income, while his time constraint is given as,

$$
\Omega=L_{t}+T_{t}=\bar{L}+\Delta L+T_{t}, t=0,1,
$$

Where $\Omega$ a total amount of hours per period is, e.g., 24 hours a day; $L$ represents work hours in period $t$, consisting of contractual work ${ }_{\text {hpours }} L$, e.g., 8 hours per day ${ }^{10}$, and overtime work hours $\Delta L{ }^{11}$; and $I_{t}$ are total leisure hours in period $t$.

Here, we assume that employee's overtime work in period 0 is intrinsically built into the individual's promotion in the firm and his promotion takes place in the second period, $t=1$. The promotion scheme is given as follows:

$$
P_{\text {pro }}=\frac{\left(L_{0}-\bar{L}\right)^{\beta}}{\bar{L}}=\frac{\Delta L^{\beta}}{\bar{L}}<1, \beta>0 \text {, }
$$

Where $P_{p r o}$ the promotion is rate; and $\beta$ represents the parameter by which the firm evaluates an employee's overtime work, which is not explicitly expressed in the labor contract between the firm and employees. If the employee wants to be promoted and,

Consequently, has higher labor earnings at $t=1$, he chooses overtime work, $\Delta L=L_{0}-\bar{L}>0$, and his promotion rate next period is positive, $0<P_{\text {pro }}<1^{12}$. On the other hand, if the employee chooses to work the contractual hours $L_{t}=\bar{L}$ at $t=0$, then the

${ }^{10}$ Contractual work hours $\bar{L}$ is called "shotei nai rodou zikan," in Japanese. ${ }^{11}$ Overtime work hours are in two types such as paid and unpaid. However, we treat hours of overtime work in this model as unpaid overtime work.

${ }^{12} \mathrm{We}$ consider a promotion for a typical employee as a movement from a lower job position to a higher one and the wage rate at a higher job position is greater than that at a lower one.

${ }^{13}$ In this definition, we avoid using a complicate health production function since our main focus here is not on a health stock function, but rather on showing how overtime work of a typical employee affects his health condition.

${ }^{14}$ Here, overtime work of a typical employee influences the probability of being

in good health as, $\frac{\partial P\left(H_{t}\right)}{\partial \Delta L}=\frac{\partial P\left(H_{t}\right)}{\partial H_{t}} \cdot \frac{\partial H_{t}}{\partial T_{t}} \cdot \frac{\partial T_{t}}{\partial \Delta L}=P_{H_{t}} \cdot H_{T} \cdot(-1)=-P_{H_{t}} H_{T}$,

where $\frac{\partial P\left(H_{t}\right)}{\partial H_{t}}=P_{H_{t}}>0$ and $\frac{\partial H_{t}}{\partial T_{t}}=H_{T}>0$. For example, in period 0 we have:

$\frac{\partial P\left(H_{0}\right)}{\partial \Delta L}=-P_{H_{0}} \alpha A T_{0}^{\alpha-1}=-\frac{P_{H_{0}} \alpha H_{0}}{T_{0}}<0$. Here, we assume $P\left(H_{t}\right)$ is subject

to the law of diminishing marginal productivity as, $\frac{\partial^{2} P\left(H_{t}\right)}{\partial H_{t}^{2}}=\frac{\partial P_{H_{t}}}{\partial H_{t}}=P_{H_{t} H_{t}}<0$.

${ }^{15}$ To simplify our model, we assume no savings are made in period 0. firm will not promote him next period such that $P_{\text {pro }}=0$ and pays the same wage rate at $t=1$ as $\bar{W}$ paid by contract at $t=0$. Here, we assume that the firm does not have enough information on the employee's aptitude for the job and, therefore, offers the same wage rate $\bar{W}$ to every employee at $t=0$ and requests the contractual labor hours, $t=$ (, per period. The wages at $t=0$ are $\bar{W} \cdot \bar{L}$ for every employee in the firm.

On the other hand, if the employee chooses to work overtime so that $P_{\text {pro }}>0$, his income at $t=1$ is $\left(1+P_{\text {pro }}\right) \bar{W} \cdot L_{1}$, where $L_{1}$ represents his work hours at $t=1$. The employee, however, faces some probability of being laid off by the firm in each period due to changes in labor market conditions, for which the market unemployment rate is proxy. Hence, the income for the employee at $t=0$ is $Y_{0}=\left(1-\phi u_{0}\right) \overline{W L}$ and the income at $t=1$ is, where $u_{t}$ is the market unemployment rate in period $t$ and $0<\phi<1$ is an employment adjustment factor in the firm in response to $u_{t} . \phi$ Is assumed to be a function of $u_{t}$ and the firm's policy is to adjust the employee's overtime work in response to changes in the market unemployment rate. That is, when the market unemployment rate is high, the firm is more willing to cut employees' overtime work such that $\frac{\partial \phi\left(u_{t}\right)}{\partial u_{t}}=\phi_{t}<0$.

Finally, we also take into consideration that the employee's health is affected by his health capital, whose value at $t=0$ is determined by the amount of hours invested in his health production as,

$$
H_{0}=A T_{0}^{\alpha}{ }^{13} \text {, }
$$

Where $H_{0}$ is the health capital of the employee at $t=0 ; A>0$ is his inherited stock of health; and $0<\alpha<0$ is the parameter reflecting the efficiency of his health production and potential ability, e.g., his productivity in the firm. In the second period, the health capital of the employee is given by $H_{1}=I_{1}+(1-\delta) H_{0}$, where $I_{1}$ is his health investment at $t=1$, which is assumed $\frac{\partial I_{1}}{\partial H_{0}}=0$ for brevity; and $0<\delta<1$ is a health depreciation rate of the employee. We assume the stock of health of the employee in each period affects the probability of being in good health, $P\left(H_{t}\right){ }^{14}$. The probability of good health in each period is assumed to influence the level of utility derived from consumption by the employee in each period, $C_{t}, t=0,1$ Since here we assume there is one type of good with the price in unity, the amount of consumption at time $t$ equals the income made by the employee at time $t$, such that $C_{t}=Y_{t}{ }^{15}$.

Now, we assume that the employee maximizes his discounted expected utility of income, as defined in equation (1), with respect to his overtime work $\Delta L$ and we have:

$$
\Delta L=\frac{\rho \beta \dot{P}_{p r o} P\left(H_{1}\right) T_{0}}{\alpha H_{0} \Pi},
$$




$$
\text { Where } \dot{P}_{p r o}=\frac{P_{p r o}}{\left(1+P_{p r o}\right)}>0 ;
$$

$\Pi=\Pi_{0}+\Pi_{1}=P_{H_{0}} \ln Y_{0}+\rho(1-\delta) P_{H_{1}} \ln Y_{1}>0$

which $\Pi_{0}=P_{H_{0}} \ln Y_{0}>0$ and $\Pi_{1}=\rho(1-\delta) P_{H_{1}} \ln Y_{1}>0$

16. Of equation (5), since we define $L_{0}=\bar{L}$ when $\Delta L=0$ and $L_{0}=\bar{L}+\Delta L$ when $\Delta L>0$, if $0<\Delta L<T_{0}$, then $0<\rho \beta \dot{P}_{p r o} P\left(H_{1}\right)<\alpha H_{0} \Pi$.

Now, first we evaluate the effects on the health of a typical employee $H_{0}$ who works overtime $\Delta L$ at $t=0 .{ }^{17}$ The health effect is as follows:

$$
\begin{aligned}
& \frac{d \ln \Delta L}{d \ln H_{0}}=\frac{T_{0}}{\bar{T}}(\Psi-1) \geq 0, \\
& \text { as } \Psi=\frac{(1-\delta) H_{0}}{H_{1}}\left(\eta_{P\left(H_{1}\right)}-\frac{\sigma_{P\left(H_{0}\right)} H_{1} \Pi_{0}+(1-\delta) \sigma_{P\left(H_{1}\right)} H_{0} \Pi_{1}}{(1-\delta) H_{0} \Pi}\right) \geq 1^{18},
\end{aligned}
$$

Where $\eta_{P\left(H_{1}\right)}=\frac{P_{H_{1}} H_{1}}{P\left(H_{1}\right)}>0$ which we call the elasticity of health probability; and $\sigma_{P\left(H_{t}\right)}=P_{H_{t} H_{t}} \frac{H_{t}}{P_{H_{t}}}<0$ is the marginal elasticity of health probability. Equation (6) indicates the sign of the health effect is ambiguous, depending on the value of $\Psi$ and the health effect is positive as long as $\Psi>1$.

With respect to the effect of promotion on overtime work, it is clear from equation (5) that $\frac{d \ln \Delta L}{d \ln P_{\text {pro }}}>0$. Thus, if overtime

${ }^{16}$ The calculation for deriving equation (5) is available upon request.

${ }^{17}$ As the reader will already have noticed, the nature of our model indicates health condition of a typical employee is simultaneously related with his overtime work. Therefore, the following comparative static analyses may seem redundant. However, the association is not necessarily self-explanatory if we assume the law of diminishing marginal probability of health.

${ }^{18}$ See Appendix for the calculation process.

${ }^{19} \mathrm{Although}$ here we are dealing with unpaid overtime work by a typical employee, this result will be the same even paid overtime work is discussed as long as overtime work is built into the promotion system in a firm.

${ }^{20}$ The effect of $\beta$ on overtime work $\Delta L$ is positive since

$\frac{\partial P_{p r o}}{\partial \beta}=\left[\frac{\left(L_{0}-\bar{L}\right)^{\beta}}{\bar{L}}\right] \ln \left(L_{0}-\bar{L}\right)=P_{p r o} \ln \left(L_{0}-\bar{L}\right)>0$

${ }^{21}$ The negative effect is obtained by incorporating the following definitions:

$\frac{d H_{0}}{d \alpha}=H_{0} \ln T_{0}>0 ; \frac{d H_{1}}{d \alpha}=(1-\delta) \frac{d H_{0}}{d \alpha}=(1-\delta) H_{0} \ln T_{0}>0 ；$

$\frac{d P_{H_{0}}}{d \alpha}=\frac{\partial P_{H_{0}}}{\partial H_{0}} \frac{\partial H_{0}}{\partial \alpha}=P_{H_{0} H_{0}} H_{0} \ln T_{0}<0 ;$ And $\frac{d P_{H_{1}}}{d \alpha}=P_{H_{1} H_{1}}(1-\delta) H_{0} \ln T_{0}<0$. work by employees is built into the system of promotion in the firm, the individual employee has an incentive to work overtime, which leads to a higher job status and consequently raises his wages next period $^{19}$. Certainly, the employee's incentive to work overtime is influenced by parameter $\beta$ in equation (3), whose value is set by the firm ${ }^{20}$. Therefore, the amount of overtime work by employees can be manipulated when there is asymmetric information on $\beta$ between the firm and employees.

Now, we will examine if a typical employee who is more efficient in producing good health tends to work overtime or not. We use $\alpha$ in equation (4) as a proxy for the employee's efficiency in the health production. The efficiency effect is negative as.

$$
\frac{d \ln \Delta L}{d \ln \alpha}=-\frac{T_{0}}{T_{1}}\left[\begin{array}{l}
1+\alpha \ln T_{0}+\frac{\alpha \ln T_{0}}{\Pi} \\
\left(\sigma_{P\left(H_{0}\right)} \Pi_{0}+\lambda(1-\delta) \sigma_{P\left(H_{1}\right)} \Pi_{1}\right)
\end{array}\right]<0,
$$

As

$$
\left|\sigma_{P\left(H_{0}\right)} \Pi_{0}+\lambda(1-\delta) \sigma_{P\left(H_{1}\right)} \Pi_{1}\right|<\Pi
$$

$0<\lambda=\frac{H_{0}}{H_{1}}<1^{21}$

If years of schooling are considered a proxy for employee's efficiency not only in his health production but also for his job aptitude in the firm, an individual with more schooling years is less likely to work overtime than a counterpart with less schooling.

Also, the effect of current income $Y_{0}$, on overtime work is negative. Through the negative income effect, an employee with higher household income will have less overtime work per period than one with lower income. In addition, the effect of health capital depreciation $\delta$ on overtime work depends on the values of both elasticity's of health probability $\eta_{P\left(H_{1}\right)}>0$ and of marginal health probability $\sigma_{P\left(H_{1}\right)}<0$. The effect is negative as long as

$\frac{\Pi_{1}}{(1-\delta) \Pi}<\lambda\left(\eta_{P\left(H_{1}\right)}-\sigma_{P\left(H_{1}\right)} \frac{\Pi_{1}}{\Pi}\right)$. If $\delta$ is positively correlated with age of employee, then employees tend to work less overtime as they have a job tenure.

Finally, we evaluate how labor market conditions affect overtime work of employees. When the market unemployment rate is high, the employee will probably be more willing to work overtime since his job security is unstable. In addition, similar to the Japanese recession, employees who keep their jobs, when their colleagues are laid off are forced to work overtime in order to take over the left tasks. Hence, an increase in layoffs in the firm will have a positive effect on overtime work in the short run.

On the other hand, the decision on overtime work by employees during a recession may not be always made solely by the employee, but may be decided in cooperation with the firm. When a recession in the economy becomes prolonged, the firm needs to reduce the overtime work of employees, which is accounted for by altering the value of the employment adjustment factor, where $0<\phi<1$ and $\frac{d \varphi}{d u_{t}}<0$. Therefore, the net 
Citation: Yamada T, Yamada T, Chen CC, Zeng W (2014) Overwork and Adverse Effects on Health. J Glob Econ 2: 106. doi:10.4172/23754389.1000106

Page 5 of 8

\begin{tabular}{|c|c|c|c|c|c|c|c|c|c|}
\hline \multirow{2}{*}{ Variable } & \multirow{2}{*}{ Definition } & \multicolumn{2}{|c|}{ All (Age: 28 - 64) } & \multicolumn{2}{|c|}{ Age : $28-39$} & \multicolumn{2}{|c|}{ Age: 40 - 49} & \multicolumn{2}{|c|}{ Age: 50 - 64} \\
\hline & & Mean & Std. Dev. & Mean & Std. Dev & Mean & Std. Dev. & Mean & St. Dev. \\
\hline ghq & health index ${ }^{a}$ & 3.929 & 2.601 & 3.892 & 2.612 & 3.904 & 2.632 & 3.972 & 2.573 \\
\hline health & health dummy (good=1, bad=0) & 0.848 & 0.359 & 0.886 & 0.318 & 0.865 & 0.341 & 0.810 & 0.393 \\
\hline twh & total working hours per month (=wkhour*wkday) & 134.342 & 92.148 & 138.278 & 91.261 & 148.050 & 86.134 & 122.479 & 95.108 \\
\hline awh & $\begin{array}{l}\text { average contractual working hours per month in prefecture in } \\
1998 .\end{array}$ & 167.268 & 2.951 & 167.079 & 2.996 & 167.464 & 2.915 & 167.275 & 2.934 \\
\hline owh & overtime working hours per month (=twh -awh), [paid work] & -32.926 & 91.565 & -28.800 & 90.553 & -19.414 & 85.478 & -44.796 & 94.656 \\
\hline Owh $(o w h>0)$ & overtime working hours per month (=twh -awh>0,) [paid work] & 47.905 & 41.699 & 46.375 & 39.198 & 50.554 & 41.493 & 47.164 & 43.850 \\
\hline unemp98 & average unemployment rate in prefecture in 1998 & 4.073 & 0.917 & 4.108 & 0.915 & 4.042 & 0.934 & 4.069 & 0.907 \\
\hline eduyr & years of education completed (=graduation age -6 ) & 12.253 & 0.430 & 13.011 & 4.502 & 12.731 & 4.146 & 11.391 & 4.168 \\
\hline speduyr & years of spouse's education completed & 12.068 & 3.208 & 12.335 & 3.423 & 12.649 & 3.192 & 11.492 & 2.954 \\
\hline jobyr & working years (=current age - age at the first job) & 12.472 & 14.046 & 12.859 & 14.265 & 12.170 & 14.009 & 12.391 & 13.910 \\
\hline pjobtype0 & type of current job: manager $=1$, otherwise $=0$ & 0.030 & 0.170 & 0.033 & 0.179 & 0.030 & 0.172 & 0.027 & 0.162 \\
\hline pjobtype1 & type of current job: employee $=1$, otherwise $=0$ & 0.420 & 0.494 & 0.421 & 0.494 & 0.420 & 0.494 & 0.418 & 0.493 \\
\hline pjobtype2 & type of current job: part-time $=1$, otherwise $=0$ & 0.122 & 0.328 & 0.126 & 0.332 & 0.118 & 0.323 & 0.122 & 0.328 \\
\hline pjobtype45 & $\begin{array}{l}\text { type of current job: self owner or employee of self owner=1, } \\
\text { otherwise }=0\end{array}$ & 0.100 & 0.298 & 0.108 & 0.310 & 0.083 & 0.276 & 0.102 & 0.303 \\
\hline pjobcon1 & content of current job: professional technology $=1$, otherwise $=0$ & 0.143 & 0.350 & 0.204 & 0.403 & 0.143 & 0.350 & 0.100 & 0.300 \\
\hline pjobcon2 & content of current job: administrative $=1$, otherwise $=0$ & 0.064 & 0.244 & 0.018 & 0.133 & 0.077 & 0.266 & 0.089 & 0.284 \\
\hline pjobcon3 & content of current job: office $=1$, otherwise $=0$ & 0.221 & 0.415 & 0.300 & 0.459 & 0.218 & 0.413 & 0.165 & 0.371 \\
\hline pjobcon4 & content of current job: sales and service $=1$, otherwise $=0$ & 0.233 & 0.423 & 0.218 & 0.413 & 0.230 & 0.421 & 0.245 & 0.430 \\
\hline pjobcon5 & content of current job: low skill=1, otherwise $=0$ & 0.281 & 0.449 & 0.234 & 0.424 & 0.280 & 0.449 & 0.315 & 0.465 \\
\hline compsize & company size & 186.281 & 370.546 & 190.386 & 374.046 & 186.836 & 374.394 & 182.948 & 365.558 \\
\hline spincome & income of spouse (in ten thousand yen) & 272.927 & 330.433 & 233.810 & 298.093 & 310.809 & 348.316 & 276.270 & 337.521 \\
\hline caredm & $\begin{array}{l}\text { care dummy ( having experience of caring the elderly }=1 \text {, } \\
\text { otherwise }=0 \text { ) }\end{array}$ & 0.142 & 0.349 & NA & NA & NA & NA & 0.337 & 0.473 \\
\hline child06 & number of children under six years old in the household & 0.161 & 0.491 & 0.496 & 0.765 & 0.035 & 0.226 & 0.001 & 0.047 \\
\hline hheaddm & head of household dummy (head=1, otherwise=0) & 0.446 & 0.497 & 0.345 & 0.475 & 0.455 & 0.498 & 0.514 & 0.500 \\
\hline marrydm & marriage dummy (married=1, otherwise $=0$ ) & 0.890 & 0.313 & 0.752 & 0.432 & 0.921 & 0.270 & 0.970 & 0.171 \\
\hline gender & gender dummy (male=1, female $=0$ ) & 0.474 & 0.499 & 0.475 & 0.500 & 0.482 & 0.500 & 0.469 & 0.499 \\
\hline city1 & size of city dummy 1 ( 13 big cities $=1$, otherwise $=0$ ) & 0.194 & 0.395 & 0.214 & 0.410 & 0.183 & 0.387 & 0.186 & 0.388 \\
\hline city2 & $\begin{array}{l}\text { size of city dummy } 2 \text { (population over } 100 \text { thousands=1, } \\
\text { otherwise }=0 \text { ) }\end{array}$ & 0.378 & 0.485 & 0.397 & 0.489 & 0.363 & 0.481 & 0.375 & 0.484 \\
\hline city3 & $\begin{array}{l}\text { size of city dummy } 2 \text { (population less than } 100 \text { thousands=1, } \\
\text { otherwise }=0 \text { ) }\end{array}$ & 0.191 & 0.393 & 0.178 & 0.383 & 0.196 & 0.397 & 0.196 & 0.367 \\
\hline observations & & \multicolumn{2}{|c|}{5482} & \multicolumn{2}{|c|}{1664} & \multicolumn{2}{|c|}{1515} & \multicolumn{2}{|c|}{2303} \\
\hline
\end{tabular}

Note:

a) The variable of this index is based on the sixteen questions on the individual's health situation such that "yes" is 1 and "no" is 0.

Source: The First National Family Research in 1998 (NFR98), The Social Science Japan Data Archive, Institute of Social Science, University of Tokyo.

Table 3: Variable List and Definition.

effect of unemployment employee overtime work depends on the strength of the positive and negative effects.

$$
\left.\frac{d \ln \Delta L}{d \ln u_{0}}\right|_{\bar{H}_{0}}=\frac{P_{H_{0}} \varphi u_{0}}{\left(1-\varphi u_{0}\right) \Pi}\left(1+\varepsilon_{\varphi}\right) \leq 0
$$

where $\varepsilon_{\varphi}=\frac{d \varphi}{d u_{0}} \frac{u_{0}}{\varphi}<0$, which is the firm's employment adjustment elasticity. In equation (8), the sign is negative if the absolute value of the adjustment elasticity is greater than one, $\left|\varepsilon_{\phi}\right|>1$.

The result of equation (8) does not take into consideration the effect of unemployment on the employee's health. The studies [5-7] indicate

${ }^{22}$ Grossman (2004) give the following reason: "One interpretation ... is that the consumer's time is an important input into the production of his or her health and that the price of this input falls in a recession (Grossman 2004)".

${ }^{23}$ The derivation of equation (9) is available upon request. unemployment does affect the health of individuals, $\frac{\partial H_{0}}{\partial u_{0}}>0{ }^{22}$.

Therefore, the total effect of unemployment on employee overtime work depends on the net effect of the above positive or negative shortrun effect and the long-run health effect as,

$$
\frac{d \ln \Delta L}{d \ln u_{0}}=\left[\begin{array}{l}
\frac{P_{H_{0}} \varphi u_{0}}{\left(1-\varphi u_{0}\right) \Pi}\left(1+\varepsilon_{\varphi}\right)+\frac{u_{0}}{H_{0}} \\
\left\{\omega \eta_{P\left(H_{1}\right)}-1-\frac{1}{\Pi}\left(\sigma_{P\left(H_{0}\right)} \Pi_{0}+\omega \sigma_{P\left(H_{1}\right)} \Pi_{1}\right)\right\} \frac{d H_{0}}{d u_{0}}
\end{array}\right]\left(\frac{T_{0}}{\bar{T}}\right)
$$

Where $0<\omega=\frac{(1-\delta) H_{0}}{H_{1}}<1$. The first term inside the

bracket on the right side of equation (9) is the short-run effect and the second term is the long-run health effect $^{23}$. If the result of equation (6) prevails then the long-run health effect is positive. In addition, the overall unemployment effect on overtime work of the employee in 
Citation: Yamada T, Yamada T, Chen CC, Zeng W (2014) Overwork and Adverse Effects on Health. J Glob Econ 2: 106. doi:10.4172/23754389.1000106

\begin{tabular}{|c|c|c|c|}
\hline & owh [paid work] & twh & $\mathrm{GHQ}$ \\
\hline Variables & 2SLS (1) & $2 S L S(2)$ & OLS \\
\hline Owh [paid work] & --- & --- & $0.030(31.87) a$ \\
\hline GHQhat & $-20.859(-5.27) a$ & $-20.903(-5.28) a$ & --- \\
\hline eduyrhat & $-11.939(-3.73) a$ & $-12.095(-3.78) a$ & --- \\
\hline unemp98 & $-6.575(-2.59) \mathrm{a}$ & $-7.369(-2.89) \mathrm{a}$ & $-0.178(-3.21) a$ \\
\hline eduyr & -- & --- & $-0.036(-3.30) a$ \\
\hline jobyr & $-0.138(-0.87)$ & $-0.163(-1.03)$ & $-0.004(-1.17)$ \\
\hline pjobtype0 & & & $0.206(0.75)$ \\
\hline pjobtype1 & --- & --- & $-0.005(-0.04)$ \\
\hline pjobtype2 & --- & --- & $0.424(2.61) a$ \\
\hline pjobtype45 & --- & --- & $0.117(0.72)$ \\
\hline pjobcon1 & $64.461(4.60) a$ & 64.979 (4.63)a & --- \\
\hline pjobcon2 & $57.904(3.91) a$ & 54.141 (3.92)a & --- \\
\hline pjobcon3 & $31.859(2.60) a$ & $32.112(2.62) a$ & --- \\
\hline pjobcon4 & 56.259 (5.31)a & 56.441 (5.33)a & --- \\
\hline pjobcon5 & $12.222(1.18)$ & $12.317(1.19)$ & --- \\
\hline compsize & $-0.001(-0.31)$ & $-0.002(-0.46)$ & $0.000(0.01)$ \\
\hline spincome & $-0.039(-4.21) a$ & $-0.039(-4.24) a$ & $-0.000(-3.68) a$ \\
\hline caredm & $-86.406(-11.81) a$ & $-86.747(-11.86) a$ & $0.049(0.31)$ \\
\hline child06 & $1.888(0.43)$ & $1.735(0.39)$ & $-0.023(-0.24)$ \\
\hline hheaddm & 27.670 (4.25)a & 27.674 ( 4.25)a & $-0.039(-0.28)$ \\
\hline marrydm & $-31.326(-3.92) a$ & $-31.326(-3.92) a$ & $-0.559(-3.56) a$ \\
\hline gender & $154.692(19.12) a$ & 156.897 (19.39)a & $0.194(1.34)$ \\
\hline city1 & $-9.461(-1.33)$ & $-11.628(-1.64)$ & $-0.255(-1.63)$ \\
\hline city2 & $-11.515(-1.97) b$ & $-12.316(-2.11) b$ & $-0.345(-2.75) a$ \\
\hline city3 & $-11.370(-1.73) c$ & $-11.588(-1.76) c$ & $-0.391(-2.70) a$ \\
\hline Constant & $83.320(1.65) c$ & $256.011(5.07) a$ & $3.678(11.72) a$ \\
\hline Observations & 5482 & 5482 & 5482 \\
\hline Left-censored & 3106 & 3106 & 3106 \\
\hline LR chi2 & 1805.50 & 1835.79 & 2269.15 \\
\hline Pseudo R2 & 0.051 & 0.052 & 0.154 \\
\hline
\end{tabular}

Note: $t$ statistics are in parentheses. a: significant at $1 \%$. b: significant at $5 \%$. c: significant at $10 \%$.

Source: The First National Family Research in 1998 (NFR98), the Social Science Japan Data Archive, Institute of Social Science, University of Tokyo.

Table 4: Regression Results (Age: 28 - 64).

equation (9) becomes smaller than the effect obtained from equation (8).

So far we have shown how overtime work of a typical employee in a firm is affected by socio-economic characteristics of the employee. However, the endogeneity problem between overtime work of employees and their health conditions is not clear from our theoretical model. Therefore, we empirically provide evidence of endogeneity between the two variables of interest in our study. The next section presents our empirical results.

\section{Empirical Results}

Our empirical regression results of overtime work and GHQ

${ }^{24}$ The variables used in this study and their definitions and statistics are reported in Table 3. There are no observations on individuals under 28 years old.

${ }^{25}$ Our health index of $\mathrm{GHQ}$ variable consists of 16 questions on health of individuals. Answer to each question takes value of either 1 or 0 . If an individual answers yes to all 16 questions, his or her GHQ becomes 16 , indicating very poor health. The data are from the first National Family Research in 1998 (NFR98). The types of 16 questions are available on request from the first author.

${ }^{26}$ We calculate overtime work (owh) by using total working hours per month (twh) minus average contractual working hours per month in prefecture in 1998 (awh). Of the sample of 5482 observations, there are 3106 individuals, whose overtime work becomes smaller than zero. Thus, we used a censored regression of Tobit model.
(General Health Questionnaire: health index) for all individuals age 28 through 64 are reported in Table 4 . The overtime work regression results for individuals grouped into three categories by age (28-39, 40-49, and 50-64) are reported in Table $5^{24}$. The GHQ health index variable follows the studies by $[8,9]$ and takes values from 0 to $16^{25}$. The value of $\mathrm{GHQ}=16$ indicates the individual is in very poor health. To avoid sample bias due to observations for individuals who report 0 working hours per month, we use Tobit regression censored variable by variable ${ }^{26}$.

\section{Results for overtime work regressions: all aged 28-64}

Of all aged 28-64 in Table 4, we first tested if the health index variable (GHQ) and years of schooling (eduyr) are endogenous to overtime work (owh) of individuals. The Tobit result for an endogeneity test for GHQ and eduyr in the owh regression shows the estimated coefficient ( $\mathrm{t}$-statistic) on the eghat variable (the residuals obtained from the first-stage estimation of the reduced form equation of GHQ is $10.867(t=5.61)$ and the estimated coefficient on the eedhat variable (the residuals obtained from the first-stage estimation of the reduced form equation of eduyr) is $6.717(\mathrm{t}=4.26)$, indicating both GHQ and eduyr are endogenous to overtime work $[10,11]$.

Specifically, the first-stage reduced form equations of GHQ and eduyr include IVs (health, speduyr and pjobtype, i.e., pjobtype0 to pjobtype45) in addition to the exogenous variables listed for unemp98 in city 3 in Table 3. The first-stage F-values of the GHQ and eduyr regressions are 20.39 and 45.94, respectively, showing the high instrument relevance. And the over identifying restriction tests of IVs (health, speduyr and pjobtype\#) of GHQ and eduyr show IVs are

\begin{tabular}{|c|c|c|c|}
\hline \multirow[b]{2}{*}{ Variables } & \multicolumn{3}{|c|}{ Owh [paid work] } \\
\hline & $\begin{array}{c}2 S L S \\
\text { (Age: } 28-39)\end{array}$ & $\begin{array}{c}2 \text { SLS } \\
\text { (Age: } 40-49)\end{array}$ & $\begin{array}{c}2 S L S \\
\text { (Age: } 50-64)\end{array}$ \\
\hline GHQhat & $-9.335(-1.17)$ & $-11.648(-1.83) b$ & $-29.937(-4.74) a$ \\
\hline eduyrhat & $-2.159(-0.30)$ & $-6.509(-1.34)$ & $-18.106(-3.61) a$ \\
\hline unemp98 & $-6.489(-1.68) c$ & $-9.119(-2.23) b$ & $-1.880(-0.40)$ \\
\hline jobyr & $0.218(0.90)$ & $-0.056(-0.23)$ & $-0.596(-2.01) b$ \\
\hline pjobcon1 & 40.739 (1.77)c & 77.901 (3.54)a & $53.018(2.16) b$ \\
\hline pjobcon2 & 39.555 (1.29) & 77.278 (3.37)a & 77.592 (2.99)a \\
\hline pjobcon3 & $10.403(0.47)$ & $29.750(1.50)$ & $43.145(2.09) \mathrm{b}$ \\
\hline pjobcon4 & $34.656(1.45)$ & $50.269(2.86) a$ & 85.757 (4.96)a \\
\hline pjobcon5 & $6.377(0.23)$ & $19.544(1.16)$ & $28.946(1.74) c$ \\
\hline compsize & $-0.000(-0.03)$ & $0.013(1.46)$ & $-0.010(-0.94)$ \\
\hline spincome & $-0.103(-5.75) a$ & $-0.043(-3.02) a$ & $0.003(0.21)$ \\
\hline caredm & NA & NA & $-83.187(-9.26) a$ \\
\hline child06 & $-0.415(-0.10)$ & $-15.997(-1.02)$ & $-78.940(-0.90)$ \\
\hline hheaddm & $38.849(4.43) a$ & $18.924(1.80) \mathrm{c}$ & $58.328(3.89) a$ \\
\hline marrydm & $-21.206(-1.81) c$ & $12.002(0.80)$ & $13.765(0.60)$ \\
\hline gender & $146.364(9.38) a$ & $140.010(11.53) a$ & $130.935(8.66) \mathrm{a}$ \\
\hline city1 & $-0.745(-0.07)$ & $-3.017(-0.24)$ & $-25.741(-1.91) c$ \\
\hline city2 & $-16.964(-1.91) c$ & $-8.852(-0.91)$ & $-14.254(-1.33)$ \\
\hline city3 & $-27.225(-2.49) b$ & $1.154(0.11)$ & $-5.851(-0.48)$ \\
\hline Constant & $-56.104(-0.46)$ & $-29.189(-0.35)$ & $82.924(1.19)$ \\
\hline Observations & 1664 & 1515 & 2303 \\
\hline Left-censored & 887 & 815 & 1404 \\
\hline LR chi2 & 890.82 & 585.51 & 524.86 \\
\hline Pseudo R2 & 0.078 & 0.057 & 0.038 \\
\hline
\end{tabular}

Note: $t$ statistics are in parentheses. a: significant at $1 \%$. b: significant at $5 \%$. c significant at $10 \%$.

Source: The First National Family Research in 1998 (NFR98), the Social Science Japan Data Archive, Institute of Social Science, University of Tokyo.

Table 5: Regression Results by Different Age Groups. 
exogenous to owh and twh. [12], since the F-value for over-identifying restriction is 0.30 and the $\chi_{(d . f)}^{2}$ value is the J-test $=1.8$ (i.e., $m F=6 \times 0.3$ ), which is smaller than $\chi_{m-k}^{2}=\chi_{6-2}^{2}=7.78$ at a $10 \%$ significance level ${ }^{27}$.

The 2SLS (1) regression result of owh (overtime work) in Table 4 shows the estimated coefficient of GHQ is $-20.859(t=-5.27)$, which is statistically significant at a 1 percent significance level. Employees reporting more health problems are less likely to have overtime work. This result is also the same when we use the variable of individual's total hours of work per month (twh) under 2SLS $(2)^{28}$. Therefore, it is clear that individuals with better health work more overtime. The coefficient of education years (eduyr) is statistically negative as theoretically predicted. That is, more efficient employees work less overtime.

Of the estimated coefficients under 2SLS (1), the variable of unemp98 (unemployment rate), reflecting labor market conditions in 1998 (when the survey data were collected), is statistically significant and negative. We show in Section III that whether an increase in the unemployment rate lowers overtime work of employees in the short run depends on the value of the firm's employment adjustment elasticity $\boldsymbol{\varepsilon}_{\phi}$ in Equation (8). Our empirical negative effect of unemp98 seems to indicate that the adjustment elasticity $\varepsilon_{\phi}$ is greater than one in absolute value. Put differently, Japanese firms seem to adjust their production of output by quickly controlling overtime work of employees as a strategy in response to changes in market conditions in the short run. On the other hand, if we take the long-run health effect via unemployment on overtime work into consideration see Equation (9), the overall marginal unemployment effect on overtime work is about 2.86, which is less than half of the short-run unemployment effect $^{29}$. In terms of the elasticity of overtime work with respect to the unemployment rate, the short-run elasticity is about 0.56 , while the

${ }^{27}$ The degrees of freedom of $\chi^{2}$ are $(\mathrm{m}-\mathrm{k})$, where $\mathrm{m}$ is the number of IVs and $\mathrm{k}$ is the number of endogenous variables in the regression (i.e., ghq and eduyr).

${ }^{28}$ Since our empirical results are nearly the same for both owh $2 S L S(1)$ and twh $2 S L S(2)$, we will discuss on those obtained from the owh regression.

$$
\begin{aligned}
& { }_{29} \frac{d \Delta L}{\text { dunemp } 98}=\frac{\partial \text { owh }}{\partial \text { unemp } 98}+\frac{\partial \text { owh }}{\partial G H Q} \frac{\partial G H Q}{\partial \text { unemp } 98}=\text {, where } \frac{\partial G H Q}{\partial \text { unemp } 98}=-0.178 \\
& -6.575+(-20.859)(-0.178)=-2.862
\end{aligned}
$$

is from the $\mathrm{GHQ}$ regression in Table 4.

${ }^{30} \mathrm{We}$ use the averages of owh and unemp98 are 47.905 and 4.073 , respectively. ${ }^{31}$ The variable of current job of employees (i.e., pjobcon\#) is an instrument explaining monthly overtime work hours of employees, while the present job type of employees (i.e., pjobtype\#) is also an instrument in explaining health of employees. Therefore, the pjobcon\# variables are in the owh (or twh) regressions, but not in the $\mathrm{GHQ}$ regressions, whereas the pjobtype\# variables are reversed. Especially, we support an idea that a choice of the type of present job by individuals is affected by their health endowment.

${ }^{32}$ For the variable of chid06 (having children under 6 years old) in the regression of only female employees (not shown in Table 4), we find the estimate coefficien is statistically significant at a 5 percent significant level with negative sign, i.e., $-25.122(\mathrm{t}=-2.03)$, which shows women with more children under 6 tend to work less overtime.

${ }^{33}$ In a work-leisure choice model, these negative effects are often explained as due to higher opportunity costs of having overtime work. In our present model, factors giving negative effects on overtime work are negatively affecting job promotion of employees in the firm, consequently influencing labor earnings, whose expected utility employees maximize.

${ }^{34}$ The estimated coefficient of the residuals of owh is $-.0017(t=-0.37)$.

${ }^{35} \mathrm{Again}$, let us note that higher value of the $\mathrm{GHQ}$ variable implies worse health condition of the individual. long-run elasticity is about $0.24^{30}$. Therefore, firms will choose to layoff rather than adjusting overtime work of employees in response to longrun market demand for their products.

The variables of current job (pjobcon\#) and firm sizes (compsize) are included in the regression to control characteristics of firms ${ }^{31}$ Except the low-skilled work (pjobcon5), professionals (pjobcon1), administrators (pjobcon2), employees in charge of office work (pjobcon3), sales (pjobcon4) are more likely to work overtime. This is also the case in a US study by $[1,2]$ who found that employees with higher job status and more responsibility, e.g., managers, tend to choose more overtime work.

Most of the socio-economic individual characteristics studied here are significantly associated with overtime work of employees. An increase in spouse income (spincome) lowers overtime work. Negative effects are also found for employees who care for the elderly at home (caredm), and are married (marrydm), whereas positive effects are with household head (hheaddm) and male work overtime (gender) ${ }^{32}$ From these results, we find that socio-economic factors which hinder promotions have negative effects on overtime work ${ }^{33}$.

\section{Results for the GHQ health index regression}

Of the GHQ (Tobit) regression in the last column in Table 4 although not reported in the table, the residuals obtained from the first-stage estimation of the reduced form equation of overtime work (owh) are not statistically significant in explaining the GHQ health index, indicating that overtime work of employees is not endogenous to their health ${ }^{34}$. We, therefore, report only the regression results of the GHQ Tobit model in Table 4, in which the estimated coefficient of overtime work (owh) is $0.030(t=31.87)^{35}$. Of the relationship between overtime work and health of employees, we consider that an increase in exogenous overtime work of employees deteriorates their health first and then the poor health condition of employees consequently reduces overtime work of employees.

The estimated coefficient for the unemployment rate (unemp98) is $-0.178(t=-3.21)$, the negative sign is congruent with the previous studies [5-7]. The effect of years of education completed (eduyr) is also negative on GHQ, implying efficient individuals are more likely to be in good health, ceteris paribus. For the other socio-economic characteristics in the GHQ regression, the estimated coefficients of income of spouse (spincome), and married (marrydm) are significantly negative. This show that good health is associated with these characteristics.

\section{Results for overtime work regressions: employees aged 28-39, 40-49, and 50-64}

In Table 5, the estimated coefficient of the GHQ health index variable is statistically significant for employees aged 40-49 and 5064, but not for those aged 28-39. Since the signs of the estimated coefficients are all negative, employees with better health are more likely to work overtime; however, this relationship is more prevalent amongst older employees. On the other hand, changes in labor market conditions influence overtime work of relatively younger employees, indicating that firms are likely to have younger employees work overtime in response to labor market conditions, i.e., fluctuations of market demand for their products.

The variable of current job (pjobcon\#) has a predominantly significant effect on their overtime work among employees aged 40-49 and 50-64. Therefore, we can expect there to be more health problems with these age groups due to excessive overtime work. Among the 
socio-economic characteristics of individuals, younger employees with higher spouse-income (spincome) work less overtime, whereas household heads (hheaddm) and males (gender) work more overtime.

In sum, most of our findings support the hypothesis. First, that overtime work of employees is built into the system of job promotion and, therefore, overtime work among Japanese employees is prevalent and has the adverse effects on their health. Second, employees with good health tend to work overtime, but excessive overtime work is likely to result in the deterioration of their health, which consequently lowers their overtime work.

Third, overtime work of employees is strongly cyclical - falling during an economic recession, which indirectly supports the evidence from US studies that health improves in a recession, since overtime work of employees deteriorates their health. Fourth, of the various socio-demographic characteristics of individuals analyzed in this study, other factors deter employees from job promotions, such as, caring for the elderly in the household and being female, cause less overtime work of employees. Finally, years of schooling have a strong negative effect on overtime work. This indicates that more efficient employees are less likely to do overtime work, ceteris paribus.

\section{Summary and Conclusion}

Japan is on the list of high longevity countries. However, a large number of health problems were reported during the 1990s and 2000s recession. Deterioration of working conditions, overtime work of employees and its adverse effects on their health, has become a hotly debated social issue. This paper focused on the relationship between overtime work and health of employees, whose related issue has been increasingly addressed in literature.

In this paper, we present a theoretical model based on our hypothesis that overtime work of employees is implicitly built into a firm's promotion system. That is, a typical employee has choices to allocate his time per period between health production and overtime work in the firm. Better health results in higher expected utility of income, while overtime work brings about higher wages through job promotion.

The following predictions are provided in our theoretical model: first, excessive overtime work will cause health deterioration of individual employees. Second, the incentives of a typical employee accepting overtime work is influenced by the parameter attached with the promotion system of a firm, ultimately leading to higher income in the next term. Third, a more efficient individual reflected by more years of education completed tends to have less overtime work per period than one with less education. Finally, the effect of the unemployment rate reflecting labor market conditions on overtime work of employees depends on the employment adjustment factor in the firm in the short run and the via-health effect in the long run.

This paper provides the empirical analysis to test our theoretical model. Our analysis used micro data of 6,985 individuals from the first National Family Research in 1998 (NFR98) made by the National Family Research of Japan (NFRJ) of the Japan Society of Family Sociology (JSFS: Nihon Kazoku Shakai Gakkai, in Japanese) and provided by the Social Science Japan Data Archive, Institute of Social Science, University of Tokyo. To avoid sample bias due to the observations for individuals who report 0 working hour per month, we use Tobit regression censored variable by variable. Our empirical results show: first, the causal chain goes from better health of employees to more overtime work and eventually to a deterioration of employee's health; second, years of education completed by individuals, reflecting efficiency at work, is negatively associated with overtime work hours. In other words, more efficient individuals tend to choose less overtime work. Third, overtime work of employees is strongly cyclical - falling during an economic recession, which indirectly supports the evidence from US studies that health improves in a recession. Fourth, among the socio-demographic individual characteristics studied here, the factors hindering job promotion of employees such as having the elderly to care at home and being female, are strongly and negatively associated with overtime work of employees.

Despite the fact that Japan enjoys high longevity, there is still room left for the government to reduce individual health problems reported in the 1990s. One way to promote health of employees is to reduce excessive overtime work of employees. This can be implemented in practice if firms and the Japanese government reconsider the present promotion systems which are not explicitly expressed in the labor contract between employers and employees. Otherwise, the health of employees who work overtime will continue to deteriorate.

\section{References}

1. Bejean S, Sultan-Taïeb H, Wolff N (2003) Modelling the Social Cost of WorkRelated Stress.

2. Brett JM, Stroh LK (2003) Working 61 plus hours a week: Why do managers do it? J Appl Psychol 88: 67-78.

3. Nishiyama K, Johnson JV (1997) Karoshi-Death form overwork: Occupationa health consequences of Japanese production management. Int J Health Serv 27: $625-641$

4. Grossman M (1972) On the concept of health capital and the demand for health. J Polit Econ 80: 223-255.

5. Gerdtham UG, Ruhm CJ (2002) Deaths rise in good economic times: evidence from the OECD. National Bureau of Economic Research Working Paper 9357.

6. Ruhm CJ (2003) Good times make you sick. J HEALTH ECON 22: 637-658.

7. Grossman M (2004) Health Economics. NBER Report.

8. Cameron AC, Trivedi PK, Milne F, Piggott J (1988) A microeconometric mode of the demand for health care and health insurance in Australia. Review of Economic Studies 55: 85-106.

9. Campbell A, Walker J, Farrell G (2003) Confirmatory factor analysis of the GHQ-12: can I see that again? Aus N Z J Psychiatry 37: 475-483.

10. Wooldridge JM (2002) Econometric analysis of cross section and panel data 11. Wooldridge JM (2003) Introductory Econometrics: A Modern Approach.

12. Stock JH, Watson MW (2003) Introduction to Econometrics, Pearson Education Inc USA. 